\title{
SPECIAL
} ARTICLES

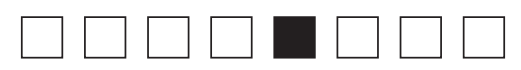

\section{The Shared Principles of Primary Care: A Multistakeholder Initiative to Find a Common Voice}

Ted Epperly, MD; Christine Bechtel, MA; Rosemarie Sweeney, MPA; Ann Greiner, MA; Kevin Grumbach, MD; Julie Schilz, MBA, BSN; Glen Stream, MD, MBI; Malachi O'Connor, PhD

\begin{abstract}
As America's health care system continues to transform, the foundational importance of primary care becomes more clear. The Joint Principles of the Patient Centered Medical Home are now more than a decade old. As delivery reform continues, the importance of seven essential shared principles have emerged from a dynamic, collaborative, and iterative process of consensus building across multiple stakeholders. These seven principles will help the public, policy makers, payers, physicians, and other clinical providers speak with a unified voice about these core principles that define the enduring essence and value of primary care. The seven shared principles of primary care consist of: (1) person and family centered, (2) continuous, (3) comprehensive and equitable, (4) team based and collaborative, (5) coordinated and integrated, (6) accessible, and (7) high value. When used together, these shared principles provide a solid platform on which to build all further health care reform.
\end{abstract}

(Fam Med. 2019;51(2):179-84.)

doi: 10.22454/FamMed.2019.925587

\section{Introduction and Rationale}

All who work in the US health care system struggle to design a more effective, efficient, accessible, highquality, and high-value enterprise. ${ }^{1,2}$ Primary care is widely acknowledged to be essential for better health and health care value and should be foundational to all health care systems. ${ }^{3-8}$ Many observers have pointed to the US health system's underinvestment in primary care as an important reason for the nation's lagging performance. ${ }^{3,9}$ Significant changes have occurred in the way primary care is organized, financed, and delivered in response to greater demand for high-quality services, rising health care costs, and increasing burden of disease across populations. ${ }^{10}$ Concepts such as the Patient
Centered Medical Home emerged to describe a more advanced model of primary care. ${ }^{11,12}$ The ongoing transformation of primary care delivery models and heightened attention to the importance of primary care have prompted fresh thinking about the essential principles that define primary care. In this article, we present an updated primary care conceptual model, the Shared Principles of Primary Care, developed by a diverse group of stakeholders representing health professionals, consumers, purchasers, and health plans. We discuss the context for developing this updated set of principles, the process for drafting them, and the implications for policy and practice.
Why Does There Need to Be a Shared Set of Primary Care Principles?

Modern-day conceptual models of primary care build on the seminal work of Barbara Starfield, JT Hart, Ian McWhinney, and Gayle Stephens, among others. Starfield affirmed that four cardinal functional attributes together define primary care: comprehensive, continuous, first contact (or accessible), and coordinated. Other scholars and organizations, such as the Institute of Medicine, ${ }^{13}$ have articulated conceptual models of primary care that are iterations of Starfield's four elements. In the early years of the 21 st century, there was growing recognition that while the core principles of primary care retained their integrity, there was a need to rethink the approach to organizing, delivering, and paying for primary care to actualize those key attributes. The concept of the Patient Centered Medical

From the Family Medicine for America's Health Engagement Tactic Team (Drs Epperly and Grumbach, and Ms Greiner); Family Medicine Residency of Idaho, Boise, ID (Dr Epperly); X4 Health, Washington, DC (Ms Bechtel); Patient-Centered Primary Care Collaborative, Washington, DC (Ms Sweeney); Department of Family and Community Medicine, University of California, San Francisco (Drs Epperly and Grumbach); Mathematica Policy Research Health Unit, Denver, CO (Ms Schilz); Family Medicine for America's Health Board of Directors (Dr Stream); and CFAR, Inc, Philadelphia, PA (Dr O'Connor). 
Home was created to characterize practice models that embraced innovations in practice design. An early version of the medical home was first described in 1967 by the American Academy of Pediatrics (AAP). In 2007, the AAP joined with three other physician organizations - the American Academy of Family Physicians (AAFP), the American College of Physicians (ACP), and American Osteopathic Association (AOA) - to issue the Joint Principles of the $\mathrm{Pa}$ tient Centered Medical Home. ${ }^{12}$ To Starfield's core principles, the Joint Principles added the principles of a personal physician, physician directed medical practice, quality and safety, and payment reform. One of the catalysts for these four organizations coming together to issue the Joint Principles was the formation in 2006 of a multistakeholder coalition, the Patient Centered Primary Care Collaborative (PCPCC), that included these physician organizations as well as employers, payers, and consumer groups. ${ }^{11}$ The Joint Principles were issued 21 months before the 2008 US presidential election and played an influential policy role as a wave of health reform proposals gathered steam in anticipation of a new administration. The Principles represented one of the first times that the four physician organizations representing different primary care specialties came together to produce a common position statement and advocacy agenda around practice redesign and value-based payment reform.

The Joint Principles informed many of the primary care policies incorporated into the Affordable Care Act and set the stage for development of Patient Centered Medical Home recognition programs administered by the National Committee for Quality Assurance (NCQA) and other organizations. The Joint Principles also came under criticism. Foremost was the complaint that it was exclusive for a group of physician organizations to brand a set of principles as "patient centered" without including patients and consumers in a prominent role in the drafting of the principles. Many nurse practitioners and other health professionals also balked at the "physician directed" precept. These criticisms, among others, impeded the realization of a set of primary care principles that could be embraced and advocated for by the broadest possible a coalition of stakeholders. In fact, these principles are not designed for one specialty or profession alone, but rather are to be the foundation for the movement of primary care to reform the way health care is both delivered and received in our country.,14

\section{Methods}

Realizing that achieving ideal primary care occurs faster when all stakeholders can speak with unity, multiple constituents came together in 2016 to launch the drafting of an updated set of primary care principles. ${ }^{15,16}$ Leaders also wanted to respond to an updated view of what contributes to health and changes in the way primary care is delivered and paid for. Two tributaries converged in this process. One was a move by the PCPCC ${ }^{11}$ to bring a broader group of stakeholders to the table to revisit the essential principles of primary care and the established Joint Principles of the Patient Centered Medical Home. Redesigning primary care to feature integrated interdisciplinary teams of health care professionals working together for the best interests of the patient, the family, and the community was central to this process.

The second was Family Medicine for America's Health (FMAHealth) ${ }_{15}^{15}$ an initiative among all the major national family medicine organizations, that included a strategic goal of more robust engagement with patients, consumers, and nonphysician health professionals. Eschewing parallel play, PCPCC and FMAHealth consolidated efforts and pledged to collaboratively draft shared principles of person-centered, team-based, high-performing primary care that will serve as the foundation of a health system designed to achieve the quadruple aim of better care, better health, lower costs, and greater joy for clinicians and staff in delivery of care. ${ }^{17}$

With these precepts in mind it was time not to replace, but to update the decade-old Joint Principles of the Patient Centered Medical Home as the practice and delivery of primary care has evolved in response to population health, reductions in health care disparities, and value-based payment.

Sponsors committed to using an inclusive process to seek input from diverse sectors and perspectives. A steering committee was established, chaired by Christine Bechtel, MA, cochair at the time of the PCPCC Patient, Family, and Consumer Center, and Julie Schilz, MBA, BSN, a nurse executive at Anthem. The steering committee consisted of 30 different organizations, including the NCQA, Blue Cross/Blue Shield, Millbank Memorial Fund, Utilization Review Accreditation Committee (URAC), Accreditation Association for Ambulatory Healthcare (AAAHC), Anthem, Patient Centered Outcomes Research Institute (PCORI), the American Osteopathic Association, the American College of Physicians, the American Academy of Pediatrics, the American Academy of Family Physicians, American Academy of Nurse Practitioners, and patient organizations.

Sponsors invested in background research, several public surveys, an inclusive in-person summit, and outreach to more than 100 organizations to iterate ideas and language on what should constitute a renewed set of shared primary care principles. Draft principles were created and refined with broad stakeholder input. Health care organizations, employers, patient and patient advocacy groups, diverse health professional groups, health plans, and others 
had a voice in the process. Sponsors invited hundreds of organizations, large and small, that have a stake in primary care to sign on and support the Shared Principles. At the time of this publication more than 300 organizations have endorsed the Shared Principles.

\section{Outcomes}

\section{The Shared Principles}

The seven Shared Principles are listed in Table 1. The collaborative process reidentified the four classic Starfield principles-continuous, comprehensive, coordinated, and accessible-along with several other important concepts. The complete text of the Shared Principles is included verbatim in Appendix 1 (https:/journals.stfm.org/media/2045/ epperly-appendix1.pdf); the list of endorsing organizations is online at https://www.pcpcc.org/principles/signers. Following are some of the most salient modifications and how they are different from other sets of primary care principles.

\section{Person and Family Centered}

The decision to replace "patient centered" with the term "person and family centered" was a very intentional one, responsive to concerns expressed by consumer advocates that the word "patient" objectified individuals in a sick or dependent role. The principles sought to move beyond the narrow framework of a disease care system to one promoting health. This first of the Shared Principles affirms an empowered partnership role for individuals and families. For example, the principle asserts that:

primary care is grounded in mutually beneficial partnerships among

\section{Table 1: The Seven Shared Principles of Primary Care}

\footnotetext{
- Person and family centered

- Continuous

- Comprehensive and equitable

- Team based and collaborative

- Coordinated and integrated

- Accessible

- High value
}

clinicians, staff, individuals, and their families, as equal members of the care team. Care delivery is customized based on individual and family strengths, preferences, values, goals, and experiences using strategies such as care planning and shared decision making. There are opportunities for individuals and their families to shape the design, operation, and evaluation of care delivery.

\section{Continuous}

This principle reiterates the longstanding precept that

dynamic, trusted, respectful, and enduring relationships between individuals, families, and their clinical team members are hallmarks of primary care.

The secret sauce of primary care is the ongoing trusting relationship between clinicians and the primary care team and individuals and families that is a healing process unto itself. This allows the importance of a sustained incremental approach over time to be foundational to dealing with acute, chronic, behavioral, and prevention-based health care problems and issues. ${ }^{18}$

\section{Comprehensive and Equitable}

This principle emphasizes important contemporary aspects of comprehensive primary care, such as behavioral and mental health as well as oral health. Primary care serves all ages, both genders, and the majority of health care problems. The principle also ties comprehensiveness to emerging concepts in health equity, calling on primary care to:

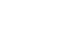

seek out the impact of social determinants of health and societal inequities. The more comprehensive the skill set and scope of practice is in the existing clinic setting the higher the percentage of problems that can be cared for in the primary care setting. Primary care practices are also recognizing the importance of the social determinants of health and linking patients who have social determinate issues (eg, food insecurity, transportation issues) with community resources that can further work with them to resolve these issues. Primary care practices partner with health and community-based organizations to promote population health and health equity, including making inequities visible and identifying avenues for solution.

Current research demonstrates that health care influences only approximately $10 \%-20 \%$ of a person's health, with a person's behaviors, environment, genetic makeup, and social conditions being the most powerful determinants of health, illness, and death. ${ }^{19}$

\section{Team Based and Collaborative} This principle affirms that individuals and families are critical members of primary care teams. In recognizing the multidisciplinary nature of team-based care, it also asserts that

health care professional members of the team are trained to work together at the top of their skill set, according to clearly defined roles and responsibilities.

This principle broadens the importance of relationships to include the entire primary care team. Many team members, from nurses, medical assistants, receptionists, social workers, nutritionists, and clinicians, form relationships with the persons and families cared for by the practice. All primary health care team members are important in the delivery of team-based collaborative care. 
This distribution of workload across the team is fundamental to decreasing clinician and health care team member burnout and increasing the joy in practice.

\section{Coordinated and Integrated}

The Shared Principles largely reiterate the central emphasis on contemporary issues such as "transitions of care to achieve better health and seamless care delivery across the life span." The term "integrated" refers to how the individual's health data and records can inform care within the primary care team and with other health care professionals in the medical neighborhood. The term "coordinated" refers to how health care is seamlessly arranged with others participating with the individual's care outside of the primary care practice in the medical neighborhood. With the emergence of evolving health information technology, new and dynamic ways of integrating and coordinating health care information and data can be performed both synchronously and asynchronously with individuals to optimize their health care and health.

\section{Accessible}

This principle acknowledges the changing nature of access in a digital communication era, asserting that:

primary care is readily accessible, both in person and virtually for all individuals regardless of linguistic, literacy, socioeconomic, cognitive, or physical barriers. This accessibility goes far beyond the concept of face-to-face visits. Meeting patients' health and health care needs electronically, telephonically, and in other technologically empowered ways is both achieving person- and family-centered care and high-value accessible care. Primary care provides individuals with easy, routine access to their health information.
Moreover, person- and family-centered access means that "clinicians and staff are available and responsive when, where, and how individuals and families need them."

\section{High Value}

This principle goes further than most prior formulations by asserting that primary care has responsibility for both quality and patient experience cost components of health care value, and once again highlights the importance of a person- and familycentered approach.

Primary care achieves excellent, equitable outcomes for individuals and families, including using health care resources wisely and considering costs to patients, payers, and the system. Primary care practices employ a systematic approach to measuring, reporting, and improving population health, quality, safety, and health equity, including partnering with individuals, families, and community groups.

Additionally, one cannot place enough value on the importance of the trusting relationship to drive quality and patient safety and to appropriately lower health care costs.

\section{Discussion}

\section{What Is New With the Shared}

Principles?

The most novel aspect of the Shared Principles was the process for creating them, which was quite different from that used for past primary care principles. This process was very inclusive and incorporated input from clinicians, payers, employers, hospitals, health care systems, patient groups, family care advocates, and other health care groups and consumer organizations. This process of involving over 100 stakeholders ensured a broad conceptualization of primary care.

In terms of content, the Shared Principles place more emphasis than prior versions on empowered and engaged individuals and families, shared decision making, asynchronous access, interprofessional teams, population health, and reducing health care disparities by understanding and addressing the social determinants of health. The Shared Principles are compatible with other schema, such as the Ten Building Blocks of High Performing Primary Care, ${ }^{20}$ the Patient Centered Medical Home recognition criteria used by NCQA and other organizations, and the eligibility criteria used by the Center for Medicare and Medicaid Innovation for the Comprehensive Primary Care Plus initiative.

\section{What Was Not Included in the Shared Principles of Primary Care?}

The Shared Principles intentionally did not address several areas, including payment models and scope of practice of team members. The principles focused on the "what" and "why" of primary care: principles that define what individuals, families, and the public should expect of primary care, and for which primary care practices should be accountable. Payment and regulatory policies are part of the "how" of primary care: factors that are the necessary enablers for primary care practices to be able to fulfill the Shared Principles. For primary care teams to achieve these aspirational principles in daily practice requires an investment of adequate resources, population-based payment models that do not merely reimburse for in-person visits, regulations that allow flexible deployment of the workforce, an infrastructure for practice improvement coaching, and other policy reforms.

\section{Implications for Practice, Policy, and Training}

An important goal for the Shared Principles is fostering a common language among diverse stakeholders 
for defining the key attributes of primary care. One of the challenges facing the field of primary care is that the meaning of the term "primary care" is not self-evident to many people-not only to the lay public, but also to many individuals working in health care and health policy. Most people understand that cardiology is the field focusing on heart and cardiovascular disease, and that surgeons and their teams perform operations. There is much less understanding of the essential features that define the practice of primary care, whether the practitioner be a family physician, general internist, pediatrician, nurse practitioner, physician assistant, or other member of the primary care workforce. The inclusive process for developing the Shared Principles was intended to promote a more consistent language for defining the attributes and expectations of primary care.

The Shared Principles may be used by practitioners to identify the ways in which their existing model accords with the Principles, and areas where their current model may not fulfill certain Principles. Patient Centered Medical Home-recognizing organizations should consider the Shared Principles as they continue to evolve and advance their recognition programs. Similarly, payers should examine the degree to which their payment policies align with and foster these attributes in primary care practice. The Shared Principles may also help to focus interprofessional education on team-based primary care. Training programs in medicine, nursing, nurse practitioner, physician assistant, nutrition, social work, psychology, dental, pharmacy, community health workers, health care administration, and other disciplines should consider how to operationalize the Shared Principles in their educational programs.

\section{Conclusion}

The United States health care system is at a critical crossroad in its transformation. The foundational importance of primary care in our future health care system cannot be overstated. The undertaking of the collaborative process of refocusing on the value of primary care by diverse stakeholders forming new partnerships both inside and outside of health care is fundamental to this effort. This shared process of principles creation across multiple stakeholders helps create a bonding covenant with our patients and the public. $^{3}$

This set of seven Shared Principles of Primary Care helps define the foundational importance of what primary care does to advance better health, a more satisfying health care experience, and more affordable costs. The Shared Principles were formulated with an understanding that they are aspirational. For them to be actualized consistently and robustly across the diverse landscape of primary care practices in the United States will require not just commitment from the primary care practice community, but also a willingness of the public, payers, and policy makers to prioritize primary care. With more than 300 organizational endorsers, the Shared Principles provide an opportunity for individuals and organizations committed to a vibrant primary care sector to speak with one voice about the bedrock elements of primary care and their importance to the health system. Although the specific ways of delivering primary care will continue to evolve as our complex health system changes, these core principles help to define the enduring essence and value of primary care.

ACKNOWLEDGMENTS: The authors acknowledge Christian Carman and the CFAR, Inc team, the staff of the PCPCC, Nicole Howard from the FMRI and the FMAHealth Board for their support on this important endeavor.

PRESENTATIONS: The Shared Principles were presented at the following meetings:

- Ohio Patient Centered Primary Care Collaborative 2017 Conference; October 27, 2017; Grove City, OH.

- American College of Osteopathic Family
Physicians Annual Convention; March 22-25, 2018; Austin, TX.

- 2018 STFM Annual Spring Conference; May 5-9, 2018; Washington, DC.

- $\quad$ AAFP Program Directors Workshop and Residency Program Symposium; April 5-9, 2018; Kansas City, MO.

CORRESPONDING AUTHOR: Address correspondence to Ted Epperly, MD, Family Medicine Residency of Idaho, 777 N Raymond, Boise, ID 83704. 208-954-8744. Fax: 208-9471761. ted.epperly@fmridaho.org.

\section{References}

1. Tandon A, Murray C, Lauer J, Evans D. Measuring overall health system performance for 191 countries. GPE Discussion Paper Series (30). 2000. World Health Organization.

2. Bishop S. Controlling health care cost. The Commonwealth Fund. https://www.commonwealthfund.org/programs/controlling-healthcare-costs. Accessed May 1, 2018.

3. Phillips RL Jr, Pugno PA, Saultz JW, et al. Health is primary: family medicine for America's health. Ann Fam Med. 2014;12(suppl 1):s1s11.

4. Mossialos E, Wenzi M, Osborn R, Anderson $\mathrm{C}$, eds. International profiles of health care systems. The Commonwealth Fund. 2015. Jan;(1802). https://www.commonwealthfund. org/sites/default/files/documents/__media files_publications_fund_report_2016_jan_1857_ mossialos_intl_profiles_2015_v7.pdf. Accessed November 13, 2018.

5. World Health Organization. The World Health Report 2008 - primary health care (now more than ever). http://www.who.int/whr/2008/en/. Accessed May 1, 2018

6. Donaldson M, Yordy K, Vanselow N, eds. Defining Primary Care: An Interim Report. Washington, DC: National Academy Press; 1994. https://www.nap.edu/read/9153/chapter/1. Accessed May 1, 2018.

7. Starfield B. Primary Care: Concept, Evaluation, and Policy. Oxford: Oxford University Press; 1992.

8. Epperly T, Roberts R, Rawaf S. Person centered primary health care: now more than ever. Int J Pers Cent Med. 2015;5(2):53-59,

9. The Commonwealth Fund. Primary care: our first line of fefense. https://www.commonwealthfund.org/publications/publication/2013/ jun/primary-care-our-first-line-defense. Published June 12, 2013. Accessed May 1, 2018.

10. Basu S, Phillips RS, Song Z, Landon BE, Bitton A. Effects of new funding models for patient-centered medical homes on primary care practice finances and services: results of a microsimulation model. Ann Fam Med. 2016;14(5):404-414.

11. Patient-Centered Primary Care Collaborative. About Us. https://www.pcpcc.org/about. Accessed May 1, 2018.

12. American Academy of Family Physicians. The Medical Home. http://www.aafp.org/practicemanagement/transformation/pcmh.html. Accessed May 1, 2018. 
13. Institute of Medicine (US) Committee on the Future of Primary Care; Donaldson MS, Yordy KD, Lohr KN, Vanselow NA, eds. Primary Care: America's Health in a New Era. Washington, DC: National Academies Press; 1996. https://www.ncbi.nlm.nih.gov/books/ NBK232643/. Accessed May 1, 2018.

14. Saultz JW. Family Medicine for America's Health: a special issue of Family Medicine. Fam Med. 2015;47(8):593-594.

15. Family Medicine for America's Health. About Us. https://fmahealth.org/about-us/. Accessed May 1, 2018.
16. Patient-Centered Primary Care Collaborative. Shared Principles of Primary Care. https:// www.pcpcc.org/about/shared-principles. Accessed May 1, 2018.

17. Institute for Healthcare Improvement. The IHI Triple Aim. http://www.ihi.org/engage/initiatives/TripleAim/Pages/default.aspx. Accessed May 1, 2018.

18. Gawande A. The heroism of incremental care New Yorker Magazine. https://www.newyorker. com/magazine/2017/01/23/the-heroism-of-incremental-care. Published January 23, 2017. Accessed November 13, 2018.
19. McGinnis JM, Foege WH. Actual causes of death in the United States. JAMA. 1993;270: 2207-12.

20. Bodenheimer T, Ghorob A, Willard-Grace R, Grumbach K. The 10 building blocks of highperforming primary care. Ann Fam Med. 2014;12(2):166-171. 